\title{
Implements Exhibited at State Fair, 1870
}

\author{
from the
}

Iowa Agricultural Report, 1870

\section{Hollingsworth's Sulky Hay Rake}

This rake is heavily timbered and ironed, and finished in superior style. It has twenty steel teeth, oil tempered, which are perfectly adjustible; with compound springs, solid iron spindles, rocker frame, and is well adapted for raking and bunching hay, gleaning stubble fields, raking corn stalks, \&c. There are over twelve thousand in use. Retail price at factory, \$45. Manufactured by John Dodds \& Co., Dayton, Ohio. Adams Brothers, Manchester, Iowa, General Agents for this State.

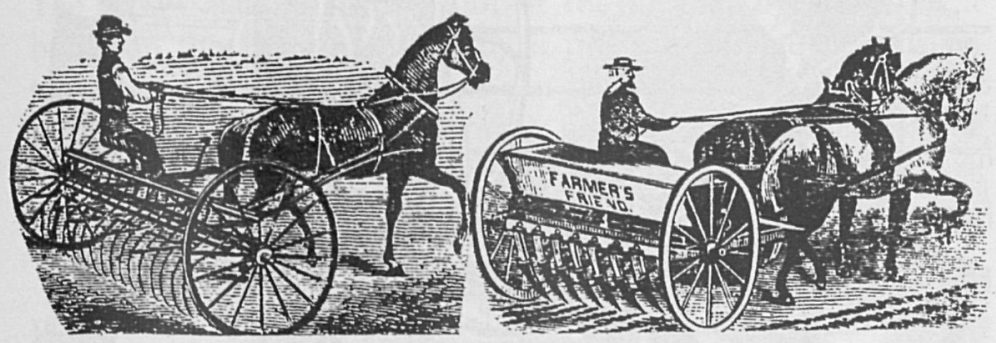

Hollingsworth’s Sulky Hay Rake

Grain Drill

\section{Grain DrLL}

This is the only forced feed grain drill which can be changed to sew more or less grain while in motion. It has no tube boards; the swinging tunnel or spout which carries the grain from the seed caps into the grain tube always follows the hoe, whether set in a line or zigzag. This arrangement enables the farmer to change the hoe from single rank to zigzag in a few minutes. Manufactured by Wensthoff \& Getz, Dayton, Ohio.

\section{The Keystone Sheller}

The Keystone Sheller where introduced is a great favorite. It is adapted to either hand or horse power; is built of good 
material, well finished, and each one is furnished with a rope pulley; its capacity, by hand, is from two hundred and fifty bushels per day; it separates the corn from the cob. A hopper is attached to each sheller for the convenience of feeding it while shelling, which can be done by a boy as well as a man. All who have used it pronounce it by far the best sheller in the market. Price, \$45. Manufactured by Keystone Manufacturing Co., Sterling, Ill.

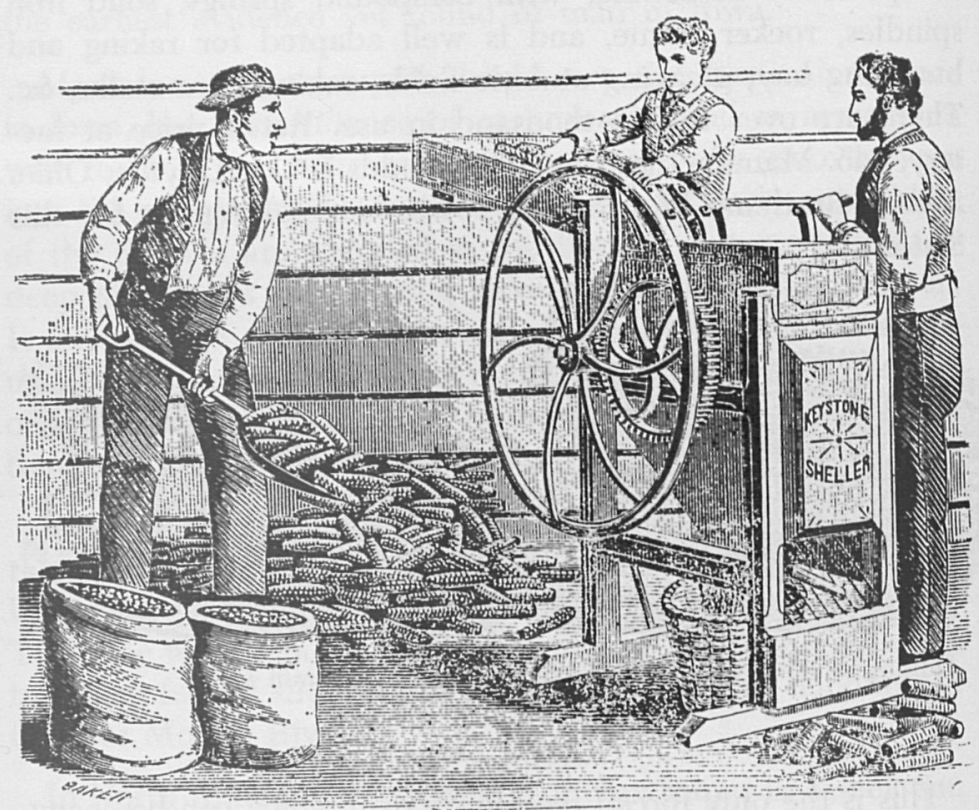

The Keystone Sheller

\section{Universal Clothes Wringer}

This wringer is constructed with two rows of cogs in the same wheel; giving an upright cog all the time while in use. It is necessary also that the cogs should be so arranged as not to play out of gear when a large article passes between the rolls; this is prevented by a patent stop or screw above the cogs, which always keeps them in place. These cogs cannot be made to backlash or ride over when hard strained, as the ordinary $\operatorname{cog}$ is so liable to do. 


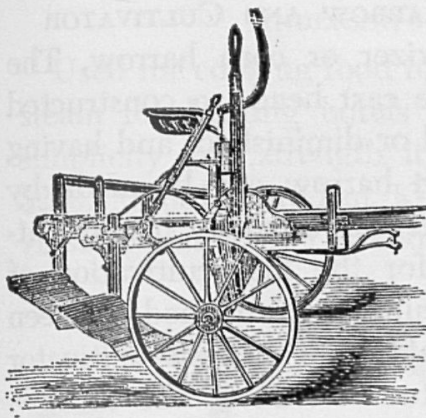

Gang Plow

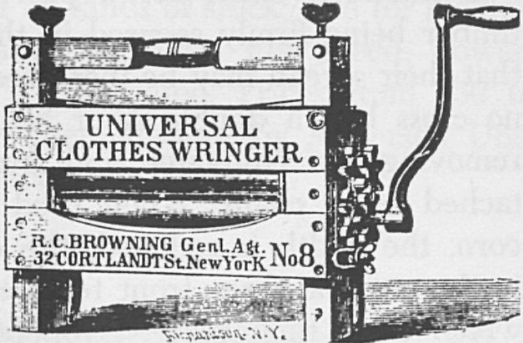

Universal Clothes Wringer

\section{Gang Plow}

Made by Robert Newton, Jerseyville, Illinois. The swing axle adapts it to uneven ground, is compact and of light draft. The plows can be thrown out of the ground by means of a brake on the furrow wheel, by a pressure of five pounds on the brake lever. Any boy that can manage a team can handle it with ease. It is simple, durable, and adapted to all kinds of plowing.

\section{The National Hand Corn Planter}

Made by Pope \& Baldwin, Quincy, Ills. It is useful to replant corn, or to plant sod or among stumps, where other planters cannot be used.

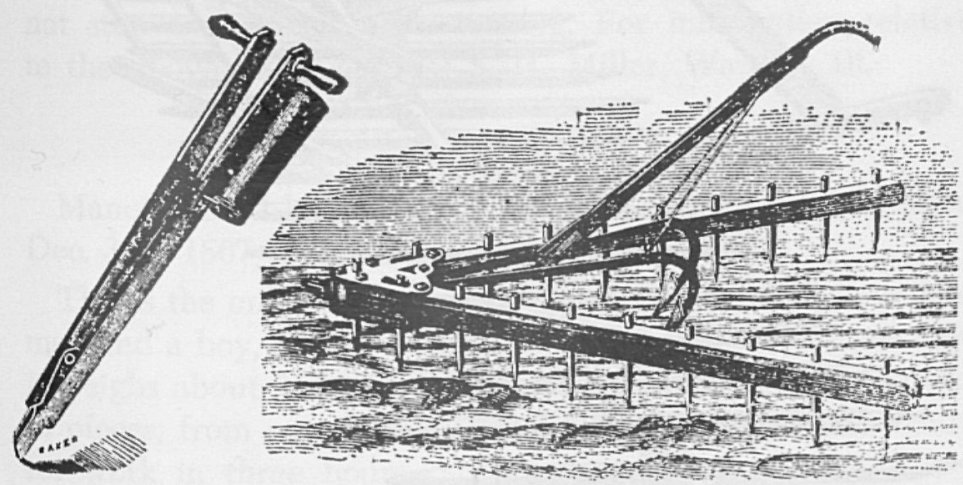

The National Hand Corn Planter
Hollingsworth's Combined Harrow and Cultivator 
Hollingsworth's Combined Harrow and Cultivator

Is intended either for a pulverizer or corn harrow. The timber being firmly secured in the cast head, so constructed that their spread may be increased or diminished, and having no cross bar, a double $\mathrm{A}$ or heart harrow can be made by removing the cultivator and inserting a small harrow attached by a chain. When used for the first cultivation of corn, the width is reduced, the cultivator attached, as seen in the cut, the three front teeth taken out and the cultivator which takes their place, is operated instead of the harrow. The weight of the head, ( $25 \mathrm{lbs}$,) by counteracting the updraught of the team, and permitting a short hitch produces a steady motion which is of great advantage. Price of complete machine, \$15.00. W. R. Hollingsworth, Mt. Pleasant, Iowa.

Revolving Hay-Rake

Revolves easily and always catches clean, and carries a full load. Is simple, durable, and compact. It is provided with two metallic springs fastened to the handles, to catch on plates fastened on the teeth and head; the handles being fastened to pendants with a pivot bolt. By this arrangement the rake can be moved and held steadily in any direction. Made by Wm. Penrose, agent, Burlington, Iowa. Huber, Gunn, \& Co., Marion, Ohio.

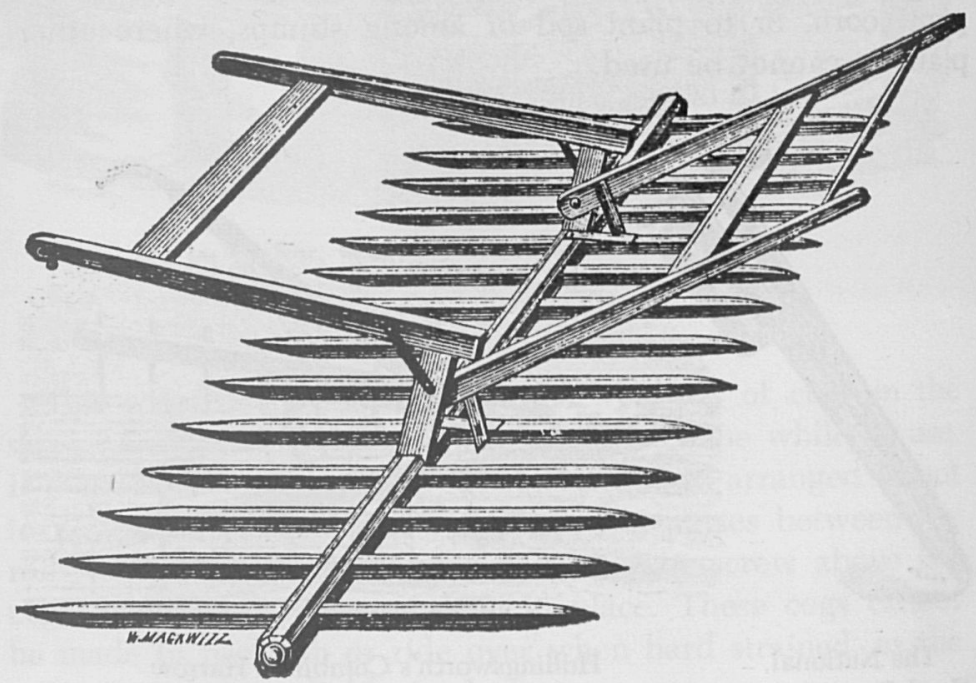

Revolving Hay Rake 


\section{Anderson's Universal Steamer}

Used for cooking food for all kinds of stock; also for making steam for heating hotels and dwellings. For speed, power; simplicity and strength it is unequaled. Prices from $\$ 50$ to $\$ 200$. Manufactured at Kewanee, Illinois, by Anderson Universal Steam Boiler Manufacturing Company.

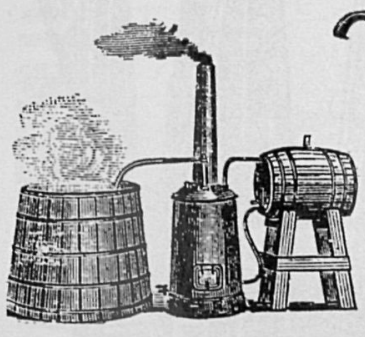

Anderson's Universal Steamer

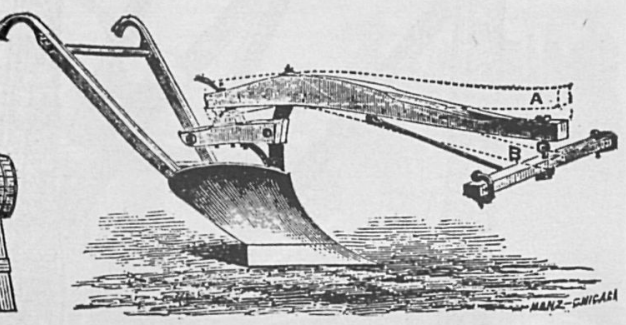

H. W. Miller's Patent Stubble Plow

\section{H. W. Mirler's Patent Stubble Plow}

It will plow under heaviest weeds, corn, or small grain stubble, without the possibility of its choking out of the ground. It has an adjustible beam, adapting it to two or three horses, and can be shifted for either; the team is hitched twelve inches nearer to it than can be done to any other plow. It suspends the double-tree, holding it the same height when the traces are slack as when plowing; the horses will not step over them when turning. For information relative to the above plow, address S. H. Miller, Warsaw, Ill.

\section{Erthel's Premium Beater Hay Press}

Manufactured by Geo. Erthel \& Co., Quincy, Ills. Patented Dec. 31st, 1867, and March 31st, 1868.

This is the only successful portable beater press in use; two men and a boy, with one horse, can make fifty bales per day, it weighs about 2,900 pounds, can be taken down and moved in pieces, from one farm to another, and set up again ready for work in three hours.

Price of the press $\$ 300.00 ; 144$ of these presses have been sold within the past three years. 


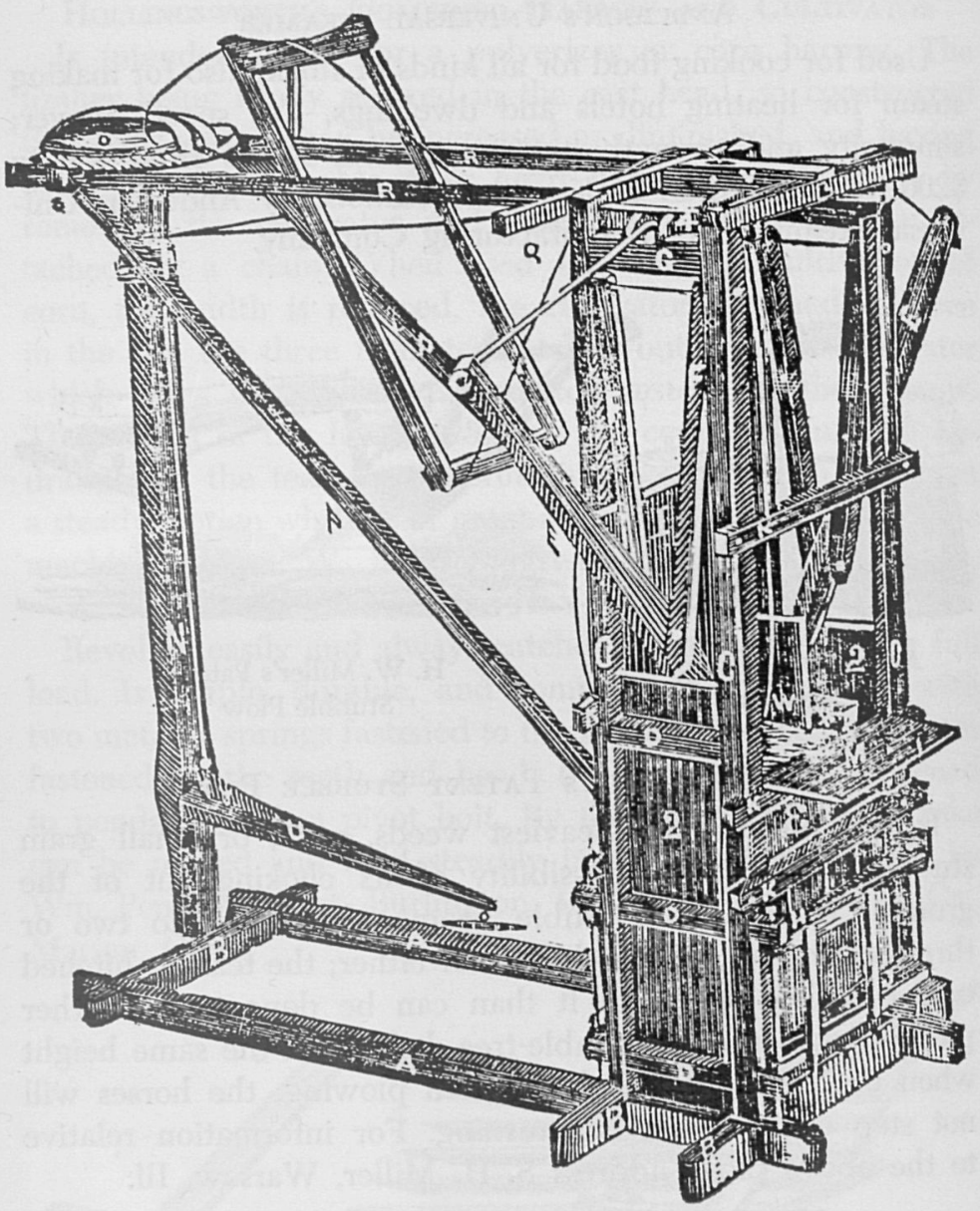

Erthel's Premium Beater Hay Press

Keystone Corn Planter

Some of the points of merit are: The shoe over the face of the runner not only regulates the depth accurately, but pulverizes the ground, thereby the corn is deposited in mellow ground free from clods; the dropping arrangement is such that the guage is stationary, while at each motion of the lever the corn is pushed over the guage, thereby insuring the guage to be filled each time; any number of grains can be dropped; the dropping can be done by a boy as well as by a man; the runners can be easily thrown out of the ground while turning 
at the end; it is of light draft. We manufacture three styles of wheel, also a marker which can be attached to the planter. Prices: wooden wheel, $\$ 60$; iron do., $\$ 65$; marker, $\$ 2.50$. Manufactured by Keystone Manufacturing Company, Sterling, Ills.

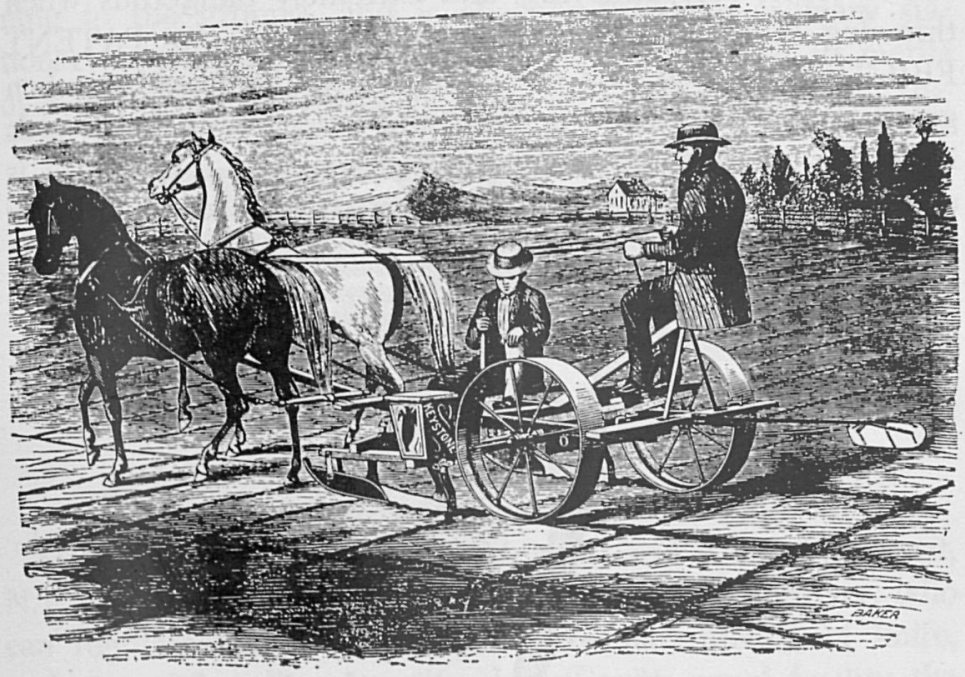

Keystone Corn Planter

\section{One Horse Grain Drill. J. B. Lutz's Patent}

It is made expressly for drilling wheat, rye, barley, or oats, if desired, in standing corn or fallow ground. It can be adjusted to the width of the rows as you pass through, and sow any quantity of seed to the acre. Retail price $\$ 30$. Made by Wayne Agricultural Company, Dublin, Indiana.

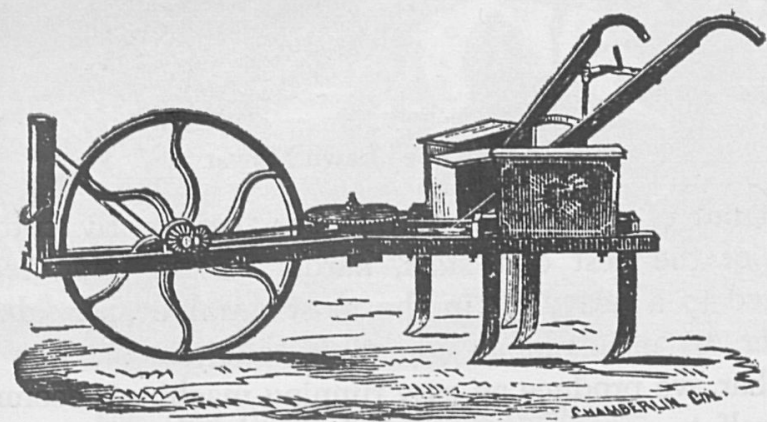

One Horse Grain Drill. J. B. Lutz's Patent 


\section{“LANDSCAPE" Lawn Mower}

The Landscape Lawn Mower embodies all the good points of other machines, while dispensing with their objectionable features. Instead of a ratchet and spring-almost sure to get out of order, very annoying, and extremely dangerous when throwing in and out of gear-we substitute our PATENT FRICTION PAROI, by means of which the machine when going forward is always in gear, and when going backwards is always out of gear, and perfectly noiseless. This parol is entirely concealed, and cannot in any possible manner break

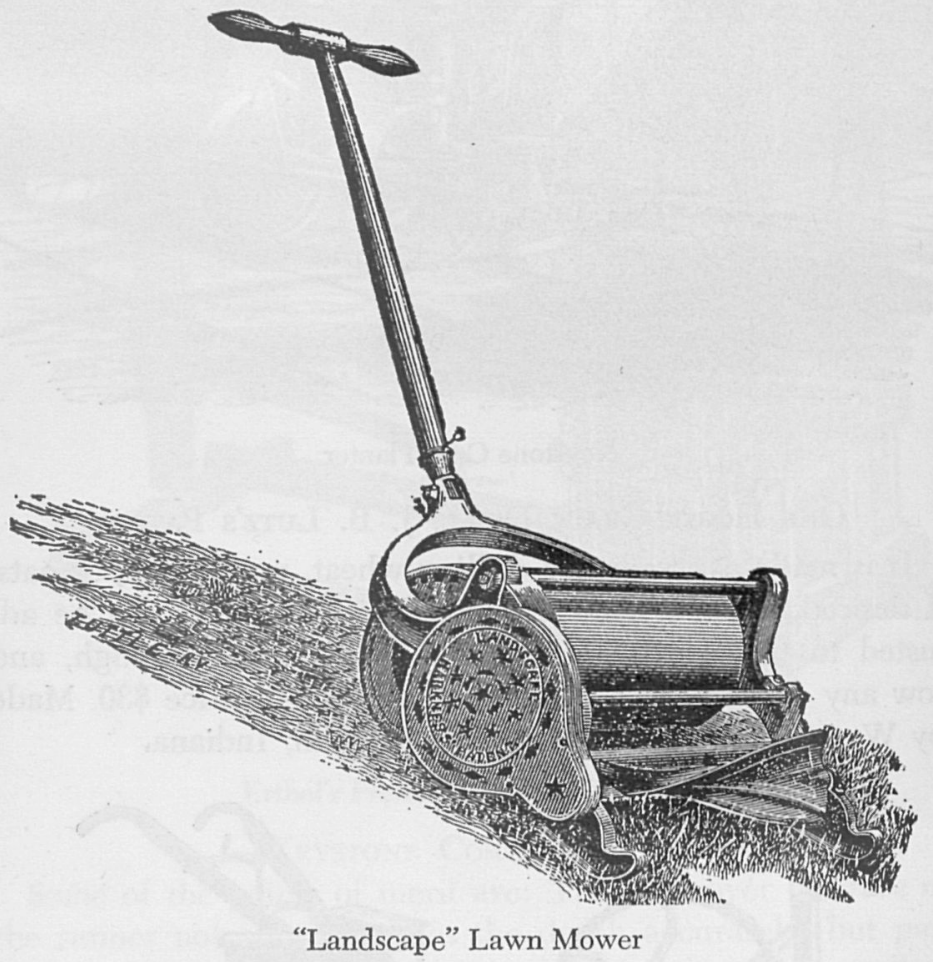

or get out of order. The cutting surfaces, or fly cutter, are made of the best cast steel, hardened and tempered, and adjusted to a heavy fly in the most durable and substantial manner. By means of an adjustible roller, in the rear of the knife bar, we produce an easy running machine, accommodating itself to any uneveness of the ground, mowing lawn or 
borders alike. Hovey \& Co., General Western Agents, 57 State street, Chicago.

\section{Portable Farm Fence}

This fence is strictly portable, requiring no staking or pinning to the ground, and is cheaper than the ordinary stationary fence; and farmers are not slow to discover its merits over all others. Patented by John W. Cheery, Carthage, Ills.

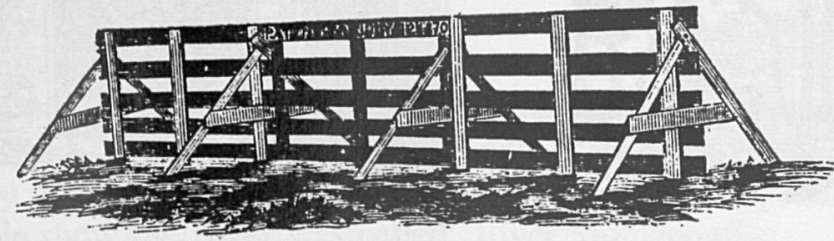

Portable Farm Fence

The "New Yorker" Self-Raking Reaper and

MOWER COMBINED

Manufactured by Seymour, Morgan, and Allen, Brockport, N.Y. The machine is under perfect control of the driver, who can regulate the height of the cutter-bar, motion of knife, and size of bundles. It will rake off with equal facility the longest and heaviest, or the shortest and lightest grain. This machine is made mostly of iron and steel, and is very durable.

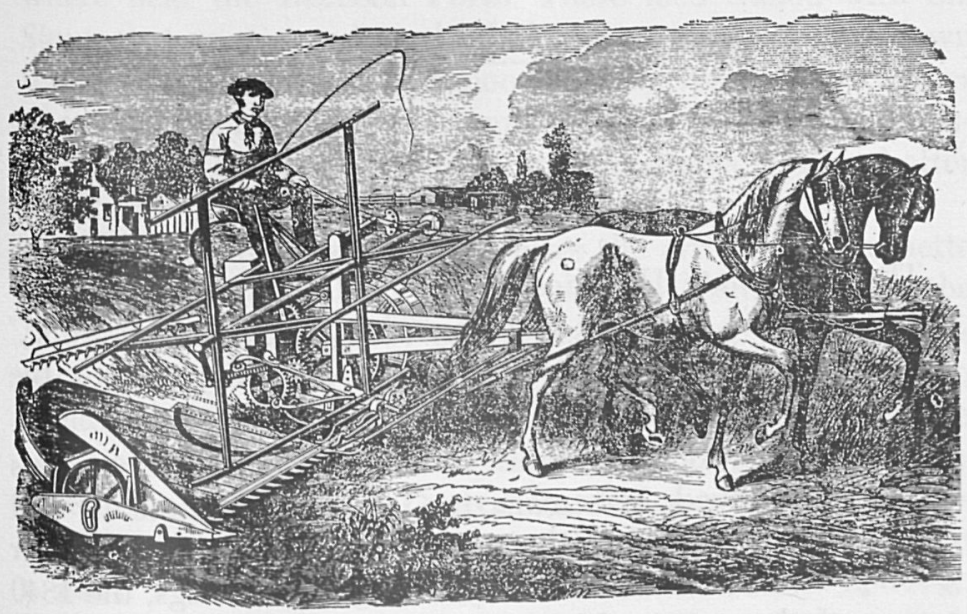

The "New Yorker" Self-Raking Reaper and Mower Combined 

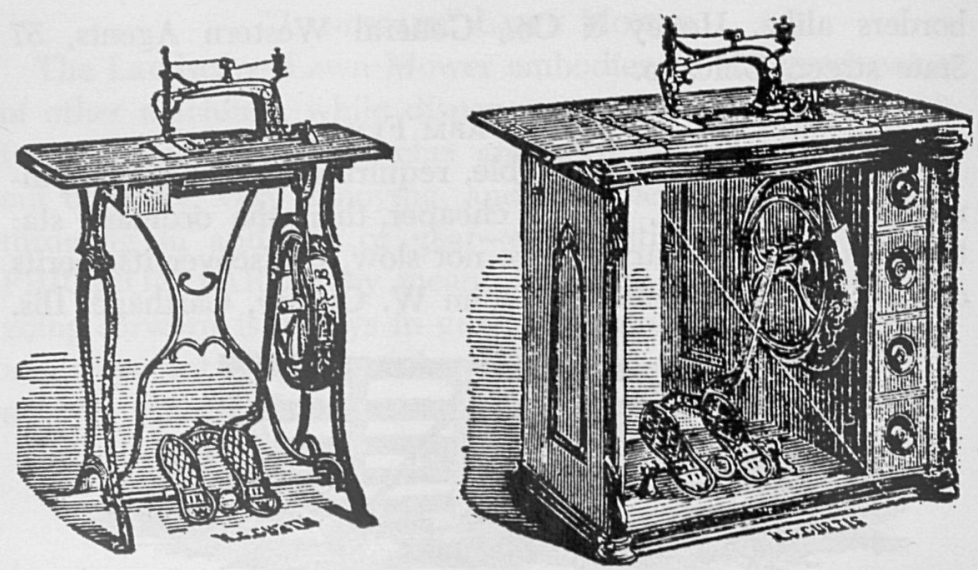

Weed Sewing Machine

\section{Weed Sewing Machine}

"Family Favorite." Walnut table-drop feed. It makes no stitch but the LOCK. The speed is superior to most making it more effective with the same effort. Runs quietly and easily. The tension is simple and the feed perfect. Complete protection against dropping of oil and soiling the dress. Price from $\$ 65.00$ to $\$ 175.00$.

\section{Library Notes}

The Iowa State Historical Library, Historical Building, recently received a family history, "The Steins of Muscatine," written by Simon G. Stein III. This genealogy traces the Steins of Muscatine to Germany back to 1645 .

The Cedar County Historical Society's 1962 Review has also been received. This magazine is published annually and consists of historical and genealogical material of Cedar County. The new issue contains, among other things, the 1840 census of the county. This was the first U. S. census of the Iowa Territory. 
Copyright of Annals of Iowa is the property of State of Iowa, by \& through the State Historical Society of Iowa and its content may not be copied or emailed to multiple sites or posted to a listserv without the copyright holder's express written permission. However, users may print, download, or email articles for individual use. 